\title{
Synthesis of a Half-Sandwich Hydroxidoiridium(III) Complex Bearing a Nonprotic $N$-Sulfonyldiamine Ligand and Its Transformations Triggered by the Brønsted Basicity
}

\author{
Shoko Kamezaki, Yoshihito Kayaki * , Shigeki Kuwata@ and Takao Ikariya \\ Department of Chemical Science and Engineering, School of Materials and Chemical Technology, Tokyo Institute \\ of Technology, 2-12-1-E4-1 O-okayama, Meguro-ku Tokyo 152-8552, Japan \\ * Correspondence: ykayaki@o.cc.titech.ac.jp; Tel.: +81-3-5734-2881
}

Received: 30 September 2019; Accepted: 15 October 2019; Published: 17 October 2019

\begin{abstract}
Synthesis and reactivities of a new mononuclear hydroxidoiridium(III) complex with a pentamethylcyclopentadienyl $\left(\mathrm{Cp}^{*}\right)$ ligand are reported. The hydroxido ligand was introduced into an iridium complex having a nonprotic amine chelate derived from $N$-mesyl- $N^{\prime}, N^{\prime}$ dimethylethylenediamine by substitution of the chloride ligand using $\mathrm{KOH}$. The resulting hydroxidoiridium complex was characterized by NMR spectroscopy, elemental analysis, and X-ray crystallography. The hydroxido complex was able to deprotonate benzamide and acetonitrile, and showed an ability to accept a hydride from 2-propanol to generate the corresponding hydrido complex quantitatively. In the reaction with mandelonitrile, a cyanide anion was transferred to the iridium center in preference to the hydride transfer. The cyanidoiridium complex was also identified in the reaction with acetone cyanohydrin, and could serve as catalyst species in the transfer hydrocyanation of benzaldehyde.
\end{abstract}

Keywords: iridium; hydroxido complex; deprotonation; hydride transfer; cyanido complex; transfer hydrocyanation; amidato complex; cyanomethyl complex

\section{Introduction}

Transition metal hydroxide complexes have received considerable attention as activators for small molecules and key intermediates in various catalytic transformations [1-3]. Despite the unmatched combination of hydroxide with a hard-base character and soft late transition metals, the utility of hydroxido complexes have been shown by careful synthetic approaches such as oxidative addition of water $[4,5]$. During the course of our studies on bifunctional catalysis based on the interconversion of amido/amine ligands [6], the O-H bond of water proved to be cleaved heterolytically by chiral amido-Ru complexes to generate amine-hydroxido complexes, and the process can contribute to the hydration of dinitriles in an enantioselective manner (Scheme 1a) [7]. Separately, we also reported the $\mathrm{C}-\mathrm{F}$ bond breaking through nucleophilic aromatic substitution with a coordinated $\mathrm{OH}$ group generated from water and bifunctional amido-Ru and -Ir complexes (Scheme 1b) [8]. In these systems, the hydroxido complexes could not be isolated, possibly because the basicity of the hydroxido ligand promoted the reverse deprotonation of the protic amine ligands to give the parent amido complexes. We conceived that structural change of the amido/amine moiety with a nonprotic amine ligand would allow to stabilize the hydroxido complexes. Under the inspiration of achievements of Cp*Ir systems [9-13], we disclose herein, the synthesis and characterization of a new mononuclear hydroxidoiridium(III) complex having $\mathrm{N}$-sulfonyldiamine without the $\mathrm{NH}$ moiety. As part from its reactivities toward 
Brønsted acids, we also deal with the cyanide transfer from cyanohydrins in relation to the hydrogen transfer from secondary alcohols.

(a)

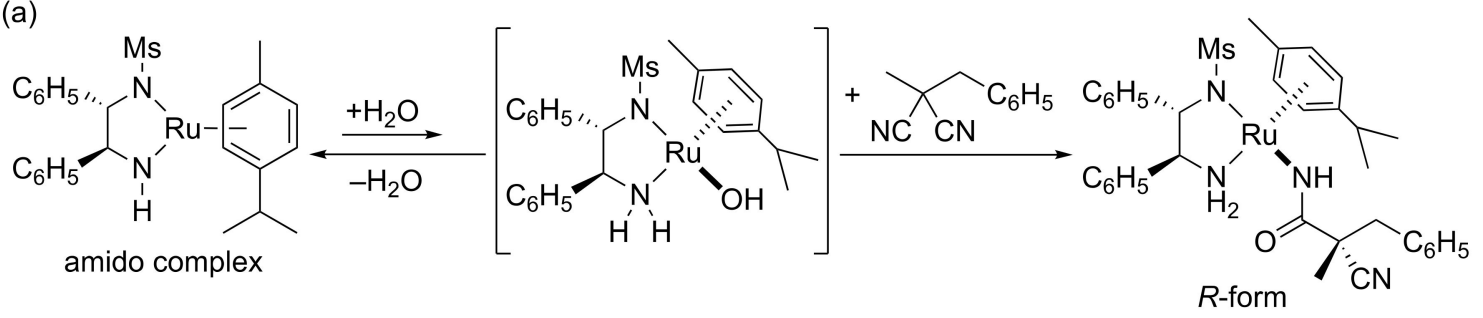

(b)

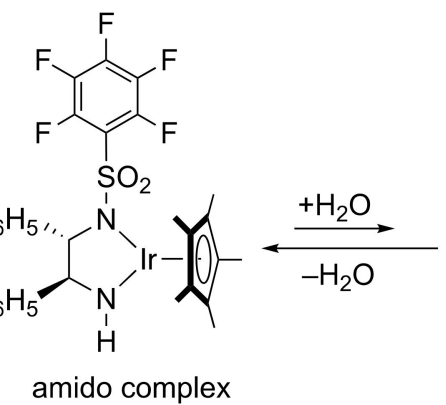

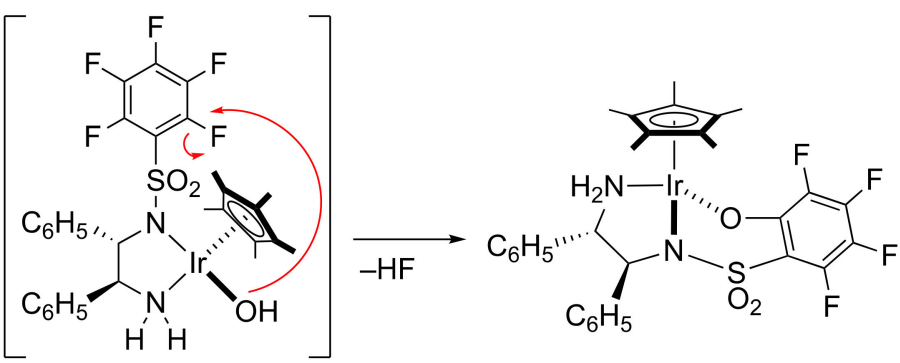

Scheme 1. Transformations via hydroxido complexes generated from amido- $\mathrm{Ru}(\mathbf{a})$ and $-\operatorname{Ir}(\mathbf{b})$ complexes in the presence of $\mathrm{H}_{2} \mathrm{O}$.

\section{Results and Discussion}

According to the established synthesis of 1,2-diphenylethylenediamine (DPEN)-derived complexes [14], coordination of $N$-mesyl- $N^{\prime}, N^{\prime}$-dimethylethylenediamine $\left(\mathrm{MsNHCH}_{2} \mathrm{CH}_{2} \mathrm{~N}\left(\mathrm{CH}_{3}\right)_{2}\right)$ with $\left[\mathrm{Cp}^{*} \mathrm{IrCl}_{2}\right]_{2}$ (diamine:Ir = 1:1) was performed in $\mathrm{CH}_{2} \mathrm{Cl}_{2}$ under basic conditions at room temperature. To avoid coordination of amine base competitively with the tertiary amine chelate, $\mathrm{KO}^{t} \mathrm{Bu}$ was better suited for the base additive. After recrystallization, the expected chlorido complex (1) was obtained as orange crystals in $49 \%$ yield (Scheme 2 ). The product was fully characterized by ${ }^{1} \mathrm{H}$ and ${ }^{13} \mathrm{C}\left\{{ }^{1} \mathrm{H}\right\}$ NMR spectra, elemental analysis, and X-ray crystallography (see the Supplementary Materials and Figure 1 (left)). A set of nonequivalent dimethylamino signals at around $3.0 \mathrm{ppm}$ in the ${ }^{1} \mathrm{H}$ NMR spectrum indicates the chelating structure of the amine ligand.
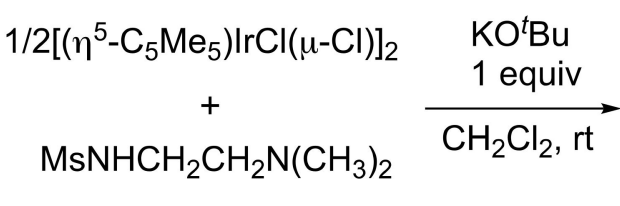

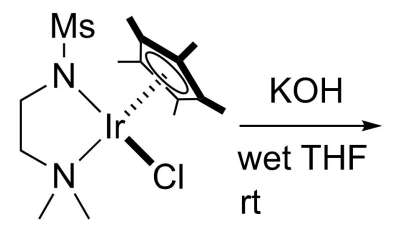

$1 ; 49 \%$

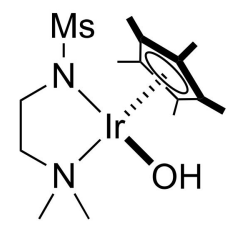

2; $42 \%$

Scheme 2. Synthesis of hydroxidoiridium 2 derived from $\mathrm{MsNHCH} \mathrm{CH}_{2} \mathrm{NMe}_{2}$.

When ligand substitution was performed by treatment of $\mathbf{1}$ with $\mathrm{KOH}$ pellets in tetrahydrofuran (THF) containing water with a $v / v$ ratio of 1500/1, the desired hydroxido-amine complex (2) was formed and successfully isolated in $42 \%$ yield after recrystallization from THF. The ${ }^{1} \mathrm{H}$ NMR spectrum in $\mathrm{CD}_{2} \mathrm{Cl}_{2}$ at $-70{ }^{\circ} \mathrm{C}$ displayed the hydroxido resonance at $-0.79 \mathrm{ppm}$ as a broad signal, which disappeared with increasing the temperature. Two separate aminomethyl signals observed at 2.83 and $2.88 \mathrm{ppm}$ were also broadened and coalesced at room temperature. These results are indicative of facile dissociation of the tertiary amine and/or hydroxido ligands, allowing for dynamic behavior. A single-crystal X-ray diffraction analysis revealed that the structure of 2 resembles that of a monomeric 
three-legged piano-stool shape of $\mathbf{1}$, as shown in Figure 1. Although the $\mathrm{OH}$ hydrogen was located from the Fourier difference map, no significant hydrogen bonding interactions were observed.
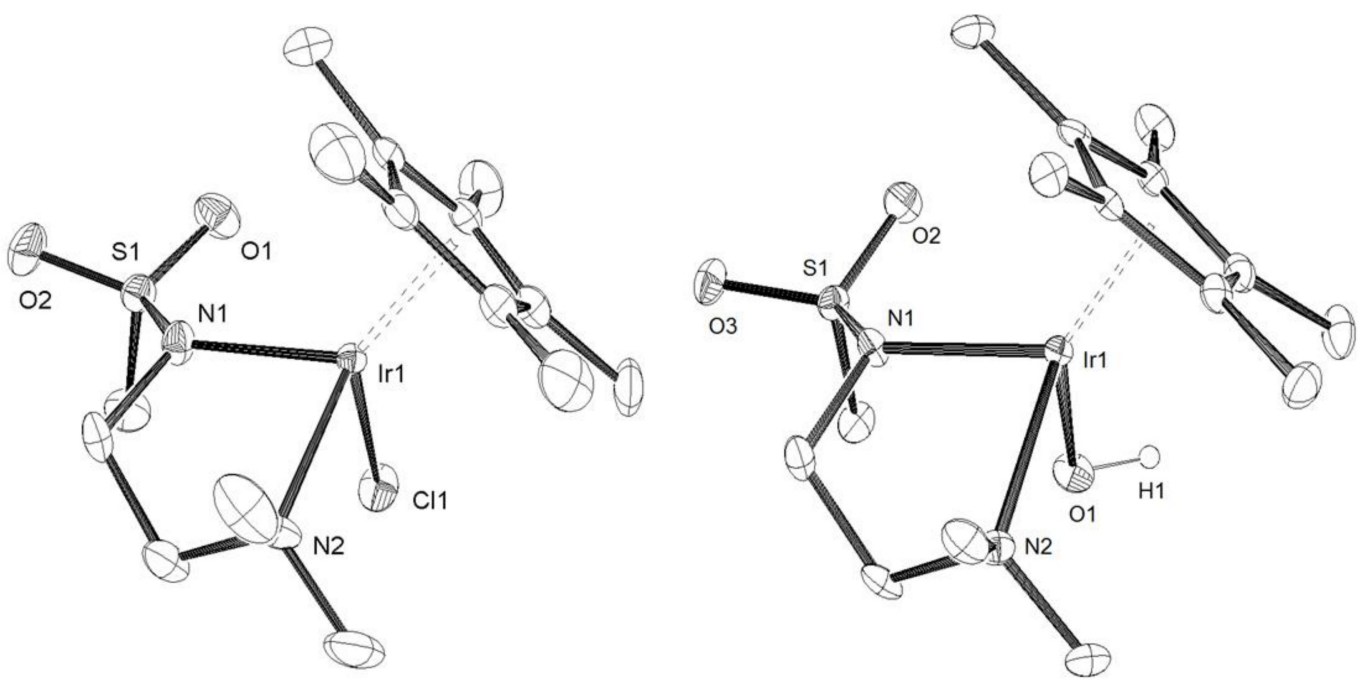

Figure 1. ORTEP drawings of $\mathbf{1}$ (left) and 2 (right). Hydrogen atoms other than the OH ligand in 2 are omitted for clarity, and the ellipsoids represent $30 \%$ probability.

The isolated mononuclear complex 2 can deprotonate benzamide to form the corresponding benzamidato (3) complex at room temperature (Scheme 3a). The ${ }^{1} \mathrm{H}$ and ${ }^{13} \mathrm{C}\left\{{ }^{1} \mathrm{H}\right\}$ NMR spectra and elemental analysis agree with the substitution. The $\kappa^{1}(N)$-benzamidato coordination making a reasonable hydrogen bond to the sulfonyl oxygen in $\mathbf{3}$ was verified by $\mathrm{X}$-ray diffraction analysis, as shown in Figure 2 (left). Moreover, the hydroxido complex proved to have sufficient basicity to abstract a proton from acetonitrile $\left(\mathrm{p} K_{\mathrm{a}}\right.$ in DMSO $\left.=31.3\right)$ [15]. When an acetonitrile solution $\left(4.0 \times 10^{-2} \mathrm{M}\right)$ of 2 was stirred at room temperature for $3.5 \mathrm{~h}$, a cyanomethyl complex (4) was isolated in $70 \%$ yield (Scheme 3b) [16]. The ${ }^{1} \mathrm{H}$ NMR spectrum in $\mathrm{CD}_{2} \mathrm{Cl}_{2}$ displayed a characteristic $\mathrm{AB}$ pattern for the diastereotopic $\mathrm{CH}_{2}$ protons of the cyanomethyl ligand at $2.14 \mathrm{ppm}$. The presence of the cyanomethyl moiety was confirmed by ${ }^{13} \mathrm{C}\left\{{ }^{1} \mathrm{H}\right\}$ NMR signals observed at -18.8 and $129.7 \mathrm{ppm}$ and a $\mathrm{CN}$ stretching band at $2187 \mathrm{~cm}^{-1}$ in the IR spectrum.

(a)

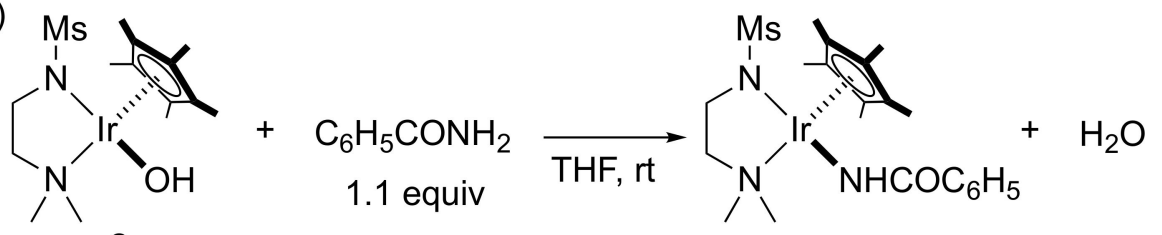

2

3; $36 \%$

(b)

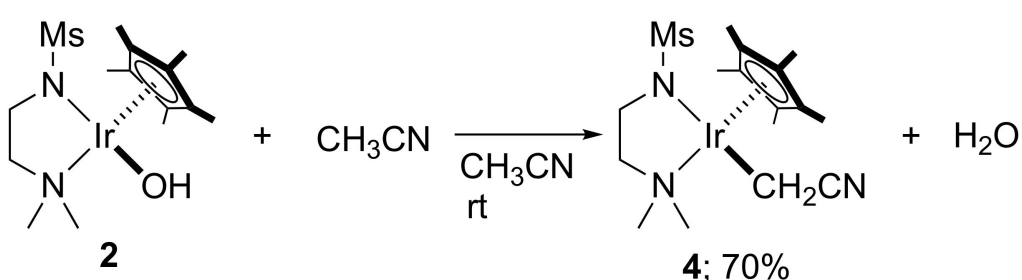

Scheme 3. Deprotonation of benzamide (a) and acetonitrile (b) with 2. 

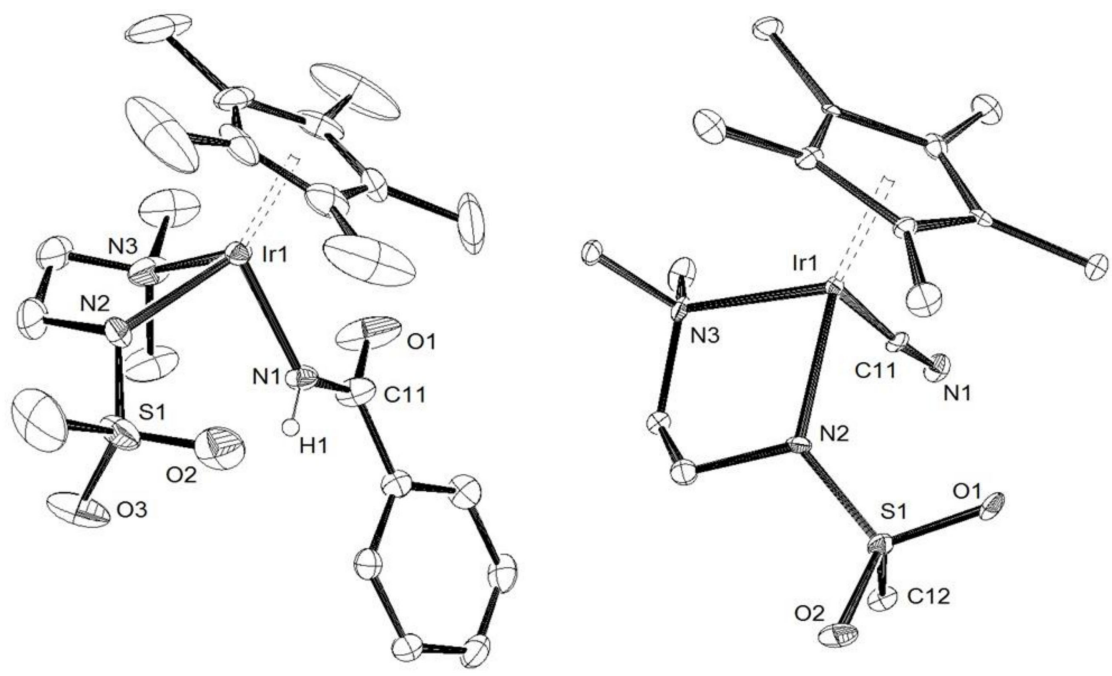

Figure 2. ORTEP drawings of 3 (left) and $\mathbf{6}$ (right). Hydrogen atoms are omitted for clarity, and the ellipsoids represent $30 \%$ probability.

Treatment of $\mathbf{2}$ in 2-propanol at ambient temperature resulted in the smooth formation of a hydrido complex (5) in an almost quantitative yield (Scheme 4). The ${ }^{1} \mathrm{H}$ NMR spectrum in $\mathrm{CD}_{2} \mathrm{Cl}_{2}$ displayed a hydrido resonance at $-11.6 \mathrm{ppm}$. Presumably, 2 deprotonated the alcohol group to generate a coordinatively saturated alkoxido complex and hemilabile nature of the tertiary amine ligand allowed spontaneous $\beta$-hydrogen elimination to afford 5 . The $\beta$-H elimination of alkoxidoiridium species generated from a hydroxido ligand was discussed with relevant to hydrogen evolution from aliphatic alcohols catalyzed by cyclometalated iridium complexes [17]. Notably, the isolable hydroxido complex 2 was found to undergo cyanide transfer from cyanohydrins in an analogous fashion to the hydride transfer (Scheme 5). Monitoring the reaction of 2 with 1 equivalent of mandelonitrile in $\mathrm{CD}_{2} \mathrm{Cl}_{2}$ at room temperature by ${ }^{1} \mathrm{H}$ NMR revealed that the hydroxido moiety was fully consumed within $30 \mathrm{~min}$ and a new cyanidoiridium complex $\mathbf{6}$ was formed in preference to the hydride transfer product $\mathbf{5}$ with the ratio of 96:4. The same complex 6 could be synthesized quantitatively by treatment of 2 with an equimolar amount of acetone cyanohydrin in $\mathrm{CH}_{2} \mathrm{Cl}_{2}$ for $30 \mathrm{~min}$ at room temperature. The product was unambiguously characterized by spectroscopic methods and elemental analysis. The cyanido ligand was identified by a ${ }^{13} \mathrm{C}$ NMR signal at $121.3 \mathrm{ppm}$ and a $\mathrm{CN}$ stretching absorption at $2103 \mathrm{~cm}^{-1}$ in the IR spectrum. Single crystal X-ray analysis also confirmed a typical half-sandwich structure of 6 as shown in Figure 2 (right). The Ir-C and C-N distances of 2.005(10) and 1.171(14) Å were nearly identical to those of 1.990(8) and 1.146(9) $\AA$ in a related cyanidoiridium complex having a TsDPEN ligand [18].

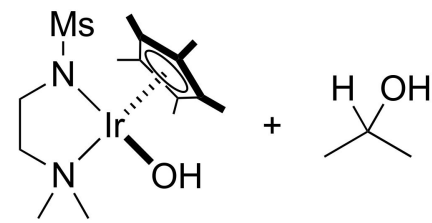

2

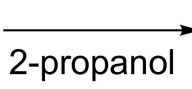
rt, $30 \mathrm{~min}$

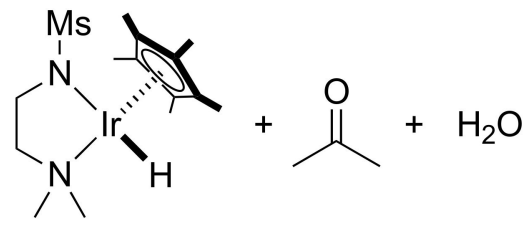

5: $99 \%$

Scheme 4. Hydrogen transfer reaction of 2 in 2-propanol. 


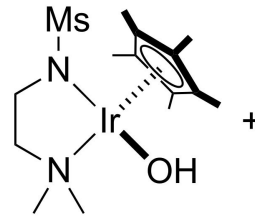

2

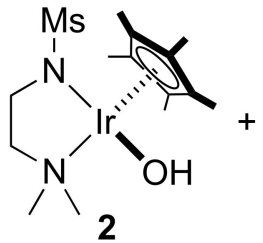<smiles>N#CC(O)c1ccccc1</smiles>

1 equiv<smiles>[R]OC(=O)O</smiles>
rt, 30 min $100 \%$ conv

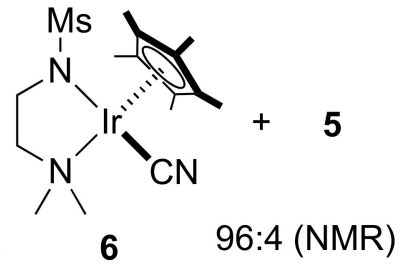

Scheme 5. Cyanide transfer from cyanohydrins using 2.

Considering the homologous hydride and cyanide transfer processes from alcoholic compounds, we envisioned that the cyanidoiridium complex will be able to promote hydrocyanation of aldehydes. In the trial reaction of benzaldehyde $(0.5 \mathrm{mmol})$ with 10 equiv of acetone cyanohydrin using $10 \mathrm{~mol} \%$ of 6 in 1,4-dioxane at $30^{\circ} \mathrm{C}$, the expected product, mandelonitrile, was reasonably formed in $69 \%$ yield after $12 \mathrm{~h}$ (Scheme 6). Hydrocyanation using acetone cyanohydrin is an attractive transformation without using hazardous $\mathrm{HCN}$ and could be operated without special setups [19,20]. Aside from successful applications in which base and Lewis acid catalysts and biocatalysts have been utilized for transfer hydrocyanation from cyanohydrin to aldehydes [21-34], transition metal-based cyanido complexes can be regarded as potential catalyst candidates to advance the $\mathrm{HCN}$-free process.

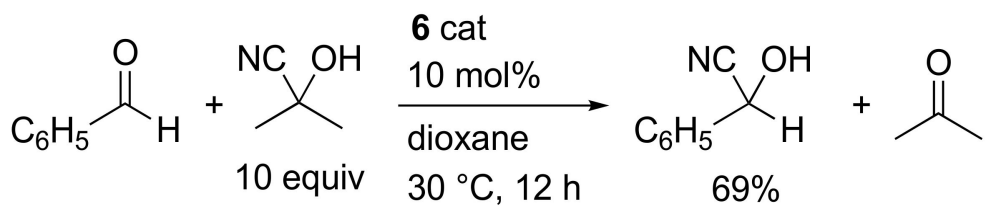

Scheme 6. Transfer hydrocyanation of benzaldehyde with acetone cyanohydrin catalyzed by 6 .

\section{Materials and Methods}

\subsection{General Information}

All manipulations of oxygen and moisture-sensitive materials were performed under a purified argon atmosphere using standard Schlenk techniques. Solvents were purchased from Kanto Chemical Co., Inc. (Tokyo, Japan) and dried by refluxing over sodium benzophenone ketyl (THF, 1,4-dioxane, and diethyl ether), $\mathrm{P}_{2} \mathrm{O}_{5}\left(\mathrm{CH}_{3} \mathrm{CN}\right.$ and $\left.\mathrm{CH}_{2} \mathrm{Cl}_{2}\right)$, or $\mathrm{CaH}_{2}$ (2-propanol), and distilled under argon before use. Chloroform- $d_{1}$ was used as delivered. Other deuterated solvents were degassed by three freeze-pump-thaw cycles and purified by trap-to-trap distillation after being dried with $\mathrm{CaH}_{2}\left(\mathrm{THF}-d_{8}\right)$ or $\mathrm{P}_{2} \mathrm{O}_{5}\left(\mathrm{CD}_{2} \mathrm{Cl}_{2}\right)$. Benzaldehyde and acetone cyanohydrin were purchased from Tokyo Chemical Industry Co., Ltd. (Tokyo, Japan), degassed, and stored under argon atmosphere. The other reagents were purchased from Sigma-Aldrich Co. LLC. (St. Louis, MO, USA), Nacalai Tesque Inc. (Kyoto, Japan), and FUJIFILM Wako Pure Chemical Corporation (Osaka, Japan), and used as delivered. ${ }^{1} \mathrm{H}$ and ${ }^{13} \mathrm{C}\left\{{ }^{1} \mathrm{H}\right\}$ NMR spectra were recorded on a JEOL JNM-LA300 and JNM-ECX400 spectrometers (JEOL Ltd., Tokyo, Japan) at around $25^{\circ} \mathrm{C}$ unless otherwise noted. The NMR chemical shifts were referenced to an external tetramethylsilane signal $(0.0 \mathrm{ppm})$ by using the signals of residual proton impurities in the deuterated solvents for ${ }^{1} \mathrm{H}$ and ${ }^{13} \mathrm{C}\left\{{ }^{1} \mathrm{H}\right\}$ NMR. IR spectra were recorded on a JASCO FT/IR-610 spectrometer (JASCO Corporation, Tokyo, Japan). Elemental analyses were carried out using a PE2400 Series II CHN analyser (PerkinElmer, Waltham, MA, USA). 


\subsection{X-Ray Crystal Structure Determination}

All measurements were made on a Rigaku Saturn 70 (Rigaku Corporation, Tokyo, Japan) using graphite-monochromated Mo-K $\alpha$ radiation $(\lambda=0.71070 \AA)$ under nitrogen stream at 193 or $93 \mathrm{~K}$. Single crystals suitable for $\mathrm{X}$-ray analyses were mounted on glass fibers. Intensity data were collected for Lorentz-polarization effects and for absorption. Details of crystal and data collection parameters for the complexes 1, 2, 3, and $\mathbf{6}$ are summarized in Tables S1 and S2. Structure solution and refinements were performed with the CrystalStructure program package [35]. The heavy atom positions were determined by a direct program method (SIR92) [36], and the remaining non-hydrogen atoms were found by subsequent Fourier syntheses and refined by full-matrix least-squares techniques against $F^{2}$ using the SHELXL-2014/7 program [37]. The OH hydrogen atom in 2 was found in the difference Fourier map, while the rest hydrogen atoms were placed at calculated positions; these hydrogen atoms were included in the refinements with a riding model.

\section{Conclusions}

In summary, the hydroxido-ligated Cp*Ir complex was successfully synthesized by employment of the nonprotic $N$-sulfonyldiamine chelate. The isolated mononuclear complex reacted with a range of protic compounds. In a striking contrast with the hydride transfer from 2-propanol, the specific cyanide transfer from cyanohydrins was demonstrated. The resulting cyanidoiridium complex can serve as the catalyst, which can deliver HCN from cyanohydrin to benzaldehyde. Further studies aimed at improving the catalytic performance, as well as exploration of the chemical properties of the related hydroxido complexes are underway.

Supplementary Materials: The following are available online at http://www.mdpi.com/2304-6740/7/10/125/s1. The CIFs and CheckCIFs; Experimental procedures and characterization of products; Tables of X-ray crystallographic data for 1, 2,3, and 6, and NMR spectra.

Author Contributions: S.K. (Shoko Kamezaki) performed experiments and measurements. Y.K. designed the experiments, carried out the X-ray crystallography, and wrote the paper. S.K. (Shigeki Kuwata) supervised and reviewed the final manuscript. T.I. supervised the project.

Funding: This research received no external funding.

Acknowledgments: We are grateful for the support from the Japan Society of Promotion of Science (JSPS) and the Sumitomo Foundation.

Conflicts of Interest: The authors declare no conflict of interest.

\section{References}

1. Gilje, J.W.; Roesky, H.W. Structurally characterized organometallic hydroxo complexes of the f- and d-block metals. Chem. Rev. 1994, 94, 895-910. [CrossRef]

2. Roesky, H.W.; Singh, S.; Yusuff, K.K.M.; Maguire, J.A.; Hosmane, N.S. Organometallic hydroxides of the transition elements. Chem. Rev. 2006, 106, 3813-3843. [CrossRef] [PubMed]

3. Nelson, D.J.; Nolan, S.P. Hydroxide complexes of the late transition metal: Organometallic chemistry and catalysis. Coord. Chem. Rev. 2017, 353, 278-294. [CrossRef]

4. Dorta, R.; Rozenberg, H.; Shimon, L.J.W.; Milstein, D. Oxidative addition of water to novel Ir(I) complexes stabilized by dimethyl sulfoxide ligands. J. Am. Chem. Soc. 2002, 124, 188-189. [CrossRef] [PubMed]

5. Ozerov, O.V. Oxidative addition of water to transition metal complexes. Chem Soc. Rev. 2009, 38, 83-88. [CrossRef] [PubMed]

6. Ikariya, T. Chemistry of concerto molecular catalysis based on the metal/NH bifunctionality. Bull. Chem. Soc. Jpn. 2011, 84, 1-16. [CrossRef]

7. Kamezaki, S.; Akiyama, S.; Kayaki, Y.; Kuwata, S.; Ikariya, T. Asymmetric nitrile-hydration with bifunctional ruthenium catalysts bearing chiral $N$-sulfonyldiamine ligands. Tetrahedron Asymmetry 2010, 21, 1169-1172. [CrossRef] 
8. Dub, P.A.; Wang, H.; Matsunami, A.; Gridnev, I.D.; Kuwata, S.; Ikariya, T.C.-F. Bond breaking through aromatic nucleophilic substitution with a hydroxy ligand mediated via water bifunctional activation. Bull. Chem. Soc. Jpn. 2013, 86, 557-568. [CrossRef]

9. Ritter, J.C.M.; Bergman, R.G. The mechanism of addition of an Ir-OH bond to ethylene. Catalytic tandem activation by two $\left[\eta^{5}-\mathrm{Cp} *(\mathrm{Ph}) \mathrm{IrPMe}_{3}\right]^{+}$complex fragments. J. Am. Chem. Soc. 1997, 119, 2580-2581. [CrossRef]

10. Hetterscheid, D.G.H.; Reek, J.N.H. Me - NHC based robust Ir catalyst for efficient water oxidation. Chem. Commun. 2011, 47, 2712-2714. [CrossRef]

11. Hintermair, U.; Hashmi, S.M.; Elimelech, M.; Crabtree, R.H. Particle formation during oxidation catalysis with Cp* iridium complexes. J. Am. Chem. Soc. 2012, 134, 9785-9795. [CrossRef] [PubMed]

12. Hintermair, U.; Sheehan, S.W.; Parent, A.R.; Ess, D.H.; Richens, D.T.; Vaccaro, P.H.; Brudvig, G.W.; Crabtree, R.H. Precursor transformation during molecular oxidation catalysis with organometallic iridium complexes. J. Am. Chem. Soc. 2013, 135, 10837-10851. [CrossRef] [PubMed]

13. Diaz-Morales, O.; Hersbach, T.J.P.; Hetterscheid, D.G.H.; Reek, J.N.H.; Koper, M.T.M. Electrochemical ans dpectroelectrochemical characterization of an iridium-based molecular catalyst for water splitting: Turnover frequencies, stability, and electrolyte effects. J. Am. Chem. Soc. 2014, 136, 10432-10439. [CrossRef] [PubMed]

14. Shirai, S.-Y.; Nara, H.; Kayaki, Y.; Ikariya, T. Remarkable positive effect of silver salts on asymmetric hydrogenation of acyclic imines with $\mathrm{Cp}^{*} \mathrm{Ir}$ complexes bearing chiral $\mathrm{N}$-sulfonylated diamine ligands. Organometallics 2009, 28, 802-809. [CrossRef]

15. Bordwell, F.G. Equilibrium acidities in dimethyl sulfoxide solution. Acc. Chem. Res. 1988, 21, $456-463$. [CrossRef]

16. Chang, H.-C.; Chang, Y.-F.; Lin, S.-H.; Lin, T.-H.; Lee, W.-Z. Ambient stable cyanomethylcopper(III) complex: A strong $\mathrm{Cu}-\mathrm{Csp}^{3}$ bond supported by a PS3-tripodal chelator. Inorg. Chem. 2019, 58, 22-26. [CrossRef]

17. Maenaka, Y.; Suenobu, T.; Fukuzumi, S. Hydrogen evolution from aliphatic alcohols and 1,4-selective hydrogenation of $\mathrm{NAD}^{+}$Catalyzed by a $[\mathrm{C}, \mathrm{N}]$ and a $[\mathrm{C}, \mathrm{C}]$ cyclometalated organoiridium complex at room temperature in water. J. Am. Chem. Soc. 2012, 134, 9417-9427. [CrossRef]

18. Letko, C.S.; Heiden, Z.M.; Rauchfuss, T.B.; Wilson, S.R. Coordination chemistry of the soft chiral lewis acid $[\mathrm{Cp} * \operatorname{Ir}(\mathrm{TsDPEN})]^{+}$. Inorg. Chem. 2011, 50, 5558-5566. [CrossRef]

19. Merino, P. $\mathrm{CN}$ addition to $\mathrm{C}=\mathrm{O}$ and $\mathrm{C}=\mathrm{N}$ bonds. In Comprehensive Organic Synthesis, 2nd ed.; Knochel, $\mathrm{P}$., Molander, G.A., Eds.; Elsevier: Amsterdam, The Netherlands, 2014; Volume 1, pp. 697-750.

20. Ye, F.; Chen, J.; Ritter, T. Rh-catalyzed anti-markovnikov hydrocyanation of terminal alkynes. J. Am. Chem. Soc. 2017, 139, 7184-7187. [CrossRef]

21. Kobayashi, Y.; Hayashi, H.; Miyaji, K.; Inoue, S. Asymmetric transcyanohydrination. Chem. Lett. 1986, 15, 931-934. [CrossRef]

22. Mori, A.; Inoue, S. A novel rate enhancement in titanium and zirconium alkoxides mediated cyano group transfers by the addition of a salycylal type schiff base, dl-3-(2-Hydroxy-1-naphthylidene)-imino- $\varepsilon$-caprolactam. A neighboring Amide Effect. Chem. Lett. 1991, 20, 145-148. [CrossRef]

23. Ohno, H.; Mori, A.; Inoue, S. Lanthanoid(III) alkoxides as novel catalysts for a rapid transhydrocyanation from acetone cyanohydrin to aldehydes and ketones. Chem. Lett. 1993, 22, 375-378. [CrossRef]

24. Kawasaki, Y.; Fujii, A.; Nakano, Y.; Sakaguchi, S.; Ishii, Y. Acetylcyanation of aldehydes with acetone cyanohydrin and isopropenyl acetate by $\mathrm{Cp}_{2}{ }_{2} \mathrm{Sm}(\mathrm{thf})_{2}$. J. Org. Chem. 1999, 64, 4214-4216. [CrossRef]

25. Ooi, T.; Takaya, K.; Miura, T.; Maruoka, $\mathrm{K} . \mathrm{Zr}\left(\mathrm{OBu}^{t}\right)_{4}$ as a new promoter for the meerwein-ponndorf-verley alkynylation and cyanation of aldehydes. Synlett 2000, 2000, 69-70.

26. Yanagisawa, A.; Matsumoto, T.; Kushihara, N.; Yoshida, K. Dibutyltin dimethoxide-catalyzed cyano transfer to aldehydes and imines. Adv. Synth. Catal. 2010, 352, 2918-2922. [CrossRef]

27. Klempier, N.; Griengl, H.; Hayn, M. Aliphatic (S)-cyanohydrins by enzyme catalyzed synthesis. Tetrahedron Lett. 1993, 34, 4769-4772. [CrossRef]

28. Nanda, S.; Kato, Y.; Asano, Y. A new (R)-hydroxynitrile lyase from Prunus mume: Asymmetric synthesis of cyanohydrins. Tetrahedron 2005, 61, 10908-10916. [CrossRef]

29. Paravidino, M.; Sorgedrager, M.J.; Orru, R.V.A.; Hanefeld, U. Activity and enantioselectivity of the hydroxynitrile lyase MeHNL in dry organic solvents. Chem. Eur. J. 2010, 16, 7596-7604. [CrossRef] 
30. Ooi, T.; Takaya, K.; Miura, T.; Ichikawa, H.; Maruoka, K. Chiral zirconium alkoxides-mediated asymmetric meerwein-ponndorf-verley cyanation of aldehydes. Synlett 2000, 2000, 1133-1134. [CrossRef]

31. Ooi, T.; Miura, T.; Takaya, K.; Ichikawa, H.; Maruoka, K. $\mathrm{Zr}\left(\mathrm{OBu}^{t}\right)_{4}$ as an effective promoter for the meerwein-ponndorf-verley alkynylation and cyanation of aldehydes: Development of new asymmetric cyanohydrin synthesis. Tetrahedron 2001, 57, 867-873. [CrossRef]

32. Watanabe, A.; Matsumoto, K.; Shimada, Y.; Katsuki, T. Oxovanadium(V)-catalyzed enantioselective meerwein-ponndorf-verley cyanation of aldehydes using acetone cyanohydrin. Tetrahedron Lett. 2004, 45, 6229-6233. [CrossRef]

33. Takaki, J.; Egami, H.; Matsumoto, K.; Saito, B.; Katsuki, T. Vanadium-catalyzed asymmetric transcyanation of aliphatic aldehydes with acetone cyanohydrin. Chem. Lett. 2008, 37, 502-503. [CrossRef]

34. Sakai, Y.; Mitote, J.; Matsumoto, K.; Katsuki, T. Room-Temperature synthesis of enantioenriched non-protected cyanohydrins using vanadium(salalen) catalyst. Chem. Commun. 2010, 46, 5787-5789. [CrossRef] [PubMed]

35. CrystalStructure 4.1: Crystal Structure Analysis Package; Rigaku Coorporation: Tokyo, Japan, 2015.

36. Altomare, A.; Cascarano, G.; Giacovazzo, C.; Guagliardi, A.; Burla, M.; Polidori, G.; Camalli, M. SIR92-A program for automatic solution of crystal structures by direct methods. J. Appl. Cryst. 1994, $27,435$. [CrossRef]

37. Sheldrick, G.M. Crystal structure refinement with SHELXL. Acta Crystallogr. Sect. C 2015, 71, 3-8. [CrossRef] [PubMed]

(C) 2019 by the authors. Licensee MDPI, Basel, Switzerland. This article is an open access article distributed under the terms and conditions of the Creative Commons Attribution (CC BY) license (http://creativecommons.org/licenses/by/4.0/). 